Gut, 1985, 26, 914-919

\title{
Gastric acid secretion and gastrin production in the short bowel syndrome
}

\author{
N S WILliaMS, P EVANS, AND R F G J KING \\ From the University Department of Surgery, The General Infirmary, Leeds
}

SUMMARY Excess gastric acid secretion and gastrin production may occur in patients with the short bowel syndrome but the two measurements have never been made simultaneously in man in response to a food stimulus. Using the technique of intragastric titration, this was carried out in eight patients after extensive small bowel resection resulting mainly from vascular occlusion and in eight matched normal control subjects. Basal acid output and peak acid output in response to pentagastrin was also measured separately. Although peak and integrated serum gastrin concentrations were significantly greater in patients $\left(450 \pm \mathrm{SE} 109 \mathrm{pg} / \mathrm{ml} ; 113 \pm 2.9 \times 10^{-3}\right.$ $\mathrm{pg} / \mathrm{ml} / \mathrm{min})$ compared with control subjects $\left(174 \pm 98 \mathrm{pg} / \mathrm{ml} ; 6 \cdot 1 \pm 2 \cdot 0 \times 10^{-3} \mathrm{pg} / \mathrm{ml} / \mathrm{min} \mathrm{p}<0 \cdot 05\right)$, no concomitant increase in acid secretion was shown either during intragastric titration or in response to pentagastrin. These findings indicate that there is no rationale for treating these patients with long term anti-ulcer therapy.

Excessive secretion of gastric acid has been shown after extensive small bowel resection in both man and experimental animals. ${ }^{1-4}$ This abnormality is considered to play an important role in the short bowel syndrome because it impairs intraluminal digestion. The low $\mathrm{pH}$ inactivates lipase, precipitates bile salts and damages small bowel mucosa. ${ }^{5}$ The effects of acid hypersecretion are considered to be so deleterious that in the past some surgeons recommended that vagotomy should be carried out simultaneously with the intestinal resection. ${ }^{67}$ With the advent of $\mathrm{H}_{2}$ receptor antagonists a more conservative approach is now suggested. ${ }^{8}$

The acid hypersecretion is usually explained on the basis of raised concentrations of serum gastrii which have been found by some investigators. ${ }^{9-11}$ This explanation can only remain a supposition, however, as these two measurements have never been made simultaneously in man in response to a meal stimulus.

The present study has used the method of intragastric titration ${ }^{12}$ to achieve this aim. In addition the opportunity was taken to confirm a previous report ${ }^{4}$ which showed in man that acid hypersecretion occurred in response to pentagastrin.

Patients who had undergone extensive small

Address for correspondence: Mr N S Williams, FRCS. University Department of Surgery, General Infirmary, Leeds LS1 3EX.

Received for publication 29 October 1984. bowel resection were compared with a group of normal control subjects. In view of the possible influence that residual Crohn's disease in the small bowel might have on gastric secretion, most of the patients studied had undergone resection as a result of vascular occlusion.

\section{Methods}

PATIENT AND CONTROL SUBJECTS

Informed consent was obtained from all subjects. Eight patients (four men and four women) were studied and compared with eight normal subjects (four men and four women) without gastrointestinal disease, matched carefully for age (patients $60 \pm \mathrm{SE}$ 4.5 years; normal subjects $63 \pm 4$ years) and body weight (patients $62 \pm 3.0 \mathrm{~kg}$; normal subjects $64 \pm 4 \cdot 6$ $\mathrm{kg}$ ). Each patient had undergone extensive resection of the distal small bowel, a mean of $5 \cdot 3$ years (range 1-16 years) previously. The reason for excision was vascular occlusion either because of thrombus or embolus (five patients), strangulation within an incisional hernia (one patient) or pressure from a mesenteric cyst (one patient). One patient who was considered to have ischaemic bowel at operation, has since been shown to have Crohn's disease. The mean length of bowel resected was 2.3 metres (range 1.4-3.8 m) as measured at operation and 1.6 metres (range $1.0 \pm 3.0 \mathrm{~m}$ ) as measured from the pathological specimen. Most patients had been 
maintained on total parenteral nutrition for a variable period after operation although this had ceased at the time of the study. Each patient did, however, complain of chronic diarrhoea.

\section{INTRAGASTRIC TITRATION STUDY}

After an overnight fast, a double lumen nasogastric tube was passed into the stomach and its position verified by the water recovery test. Basal gastric secretion was aspirated by continuous suction at 7-12 $\mathrm{mm} \mathrm{Hg}$ negative pressure with a vacuum pump. Residual juice was collected for 15 minutes and discarded, basal secretion was then collected for four 15 minute periods. Basal acid concentration was determined by titration of $0.2 \mathrm{ml}$ of juice with $0 \cdot 2 \mathrm{~N} \mathrm{NaOH}$ to $\mathrm{pH} 7 \cdot 0$.

A liquid test meal was prepared ${ }^{12}$ by dissolving four standard red Oxo cubes (Brooke Bond Group plc) in $400 \mathrm{ml}$ of water at $37^{\circ}$ giving a $6.25 \%$ wv solution. The $\mathrm{pH}$ was adjusted to 5.5 by addition of $0.2 \mathrm{~N} \mathrm{NaOH}$ if required. Validation experiments showed that the osmolarity of the meal and the concentration of its constituents were reproducible. The coefficients of variation in the content of sodium, fat and nitrogen after solution, were $2.3 \%$, $7.8 \%$ and $4.3 \%$ respectively.

Each meal was instilled into the stomach through one limb of the nasogastric tube by gravity over two minutes. After each meal, gastric acid secretion was measured for 60 minutes by the technique of intragastric titration ${ }^{13}$ as modified by Lam et $a i^{14}$ (Fig. 1).

Briefly this involved continually mixing the gastric contents by removing and reinstilling $30 \mathrm{ml}$ aliquots seven times per minute with an automatic syringe. The gastric contents were passed over a combined $\mathrm{pH}$ and reference electrode and intragastric $\mathrm{pH}$ was maintained at 5.5 with an automatic titrator which instilled $0.5 \mathrm{~mol} / 1 \mathrm{NaOH}$ from an automatic burette through the other limb of the nasogastric tube. The number of mmol of $\mathrm{HC} 1$ secreted was assumed to be equal to the number of mmol of $\mathrm{NaOH}$ necessary to maintain intragastric $\mathrm{pH}$ at $5 \cdot 5$.

After 60 minutes gastric contents were completely aspirated and the residual volume measured. Six millilitre samples of blood were taken from an antecubital vein at $0,5,10,15,30,45$, and 60 minutes. Each specimen was allowed to clot in a glass tube for one to two hours at room temperature. The clots were rimmed, the tube centrifuged and an aliquot of serum was stored at $-20^{\circ} \mathrm{C}$ for subsequent assay. The procedure used was that described by Stadil et al ${ }^{15}$ and under these conditions no alteration in gastrin content occurs because of either temperature or protease activity before separation and storage. ${ }^{16}$ Serum gastrin was measured by radio immunoassay using the unique high

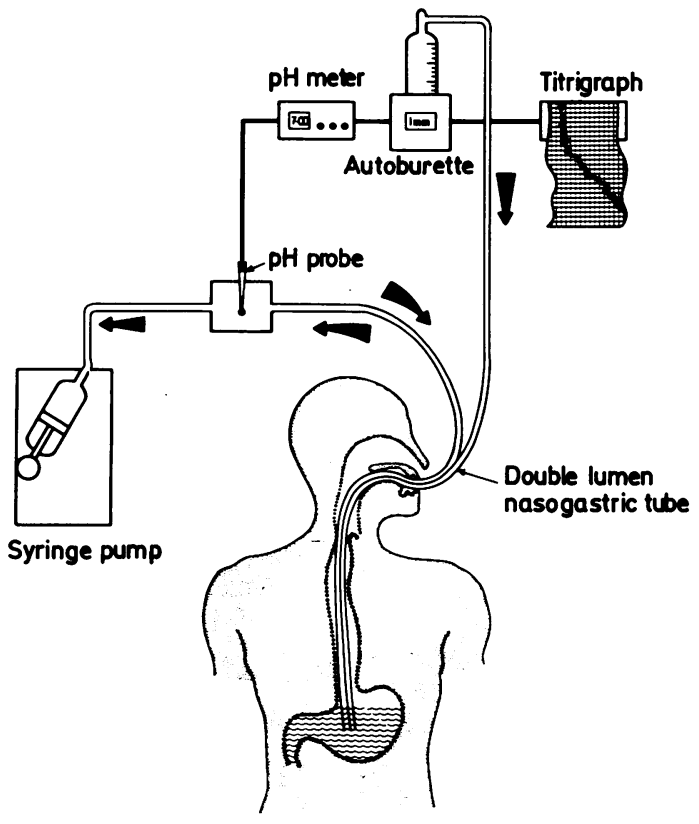

Fig. 1 Technique of intragastric titration.

titre antiserum (AB4362) found by Rehfeld. ${ }^{17}$ This antibody has a high specificity for both the $G_{17}$ and $\mathrm{G}_{34}$ forms of gastrin.

\section{ASPIRATION STUDY}

On a separate day basal acid output (BAO) was measured as previously described and in addition pentagastrin acid output (PAO) in response to 6 $\mathrm{ug} / \mathrm{kg}$ of pentagastrin administered subcutaneously was determined. ${ }^{18}$

\section{STATISTICAL ANALYSIS}

Differences in serum gastrin concentration and acid output between the two groups were analysed by the Wilcoxon's sum of ranks test for unpaired data. Correlation between measurements were analysed by Spearman's rank correlation. ${ }^{19}$ All results were expressed as mean $\pm \mathrm{SE}$.

\section{Results}

\section{INTRAGASTRIC TITRATION STUDY}

Acid output

The mean cumulative acid outputs are shown in Figure 2. There was a linear increase in acid output per unit time in both groups of subjects but no significant difference was demonstrated between them. The maximum acid output - that is, the total 


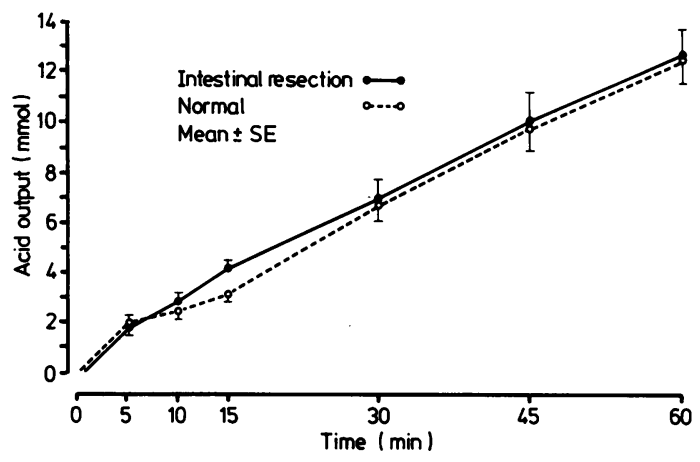

Fig. 2 Cumulative acid output during period of intragastric titration. No significant difference between the groups.

acid secreted throughout the 60 minute period, in the patients was $12.3 \pm 3.4 \mathrm{mmol}$ and in the control subjects was $12 \cdot 4 \pm 3 \cdot 2 \mathrm{mmol}$.

\section{Serum gastrin concentrations}

Mean fasting level of gastrin in patients was greater than in control subjects $107 \pm 59 \mathrm{pg} / \mathrm{min}: 14 \cdot 9 \pm 7 \cdot 8$ $\mathrm{pg} / \mathrm{min}$ respectively $(\mathrm{p}<0 \cdot 06)$.

After ingestion of the meal, serum gastrin increased and reached a peak in both patients and controls at 5-10 minutes (Fig. 3).

The integrated gastrin response (calculated as the change in gastrin $\times$ time in minutes) was significantly greater in patients compared with controls, $113 \pm 2.9 \times 10^{-3} \mathrm{pg} / \mathrm{ml} / \mathrm{min}$ and $6 \cdot 1 \pm 2 \cdot 9 \times 10^{-3} \mathrm{pg} / \mathrm{ml} /$ min respectively $(\mathrm{p}<0.05)$.

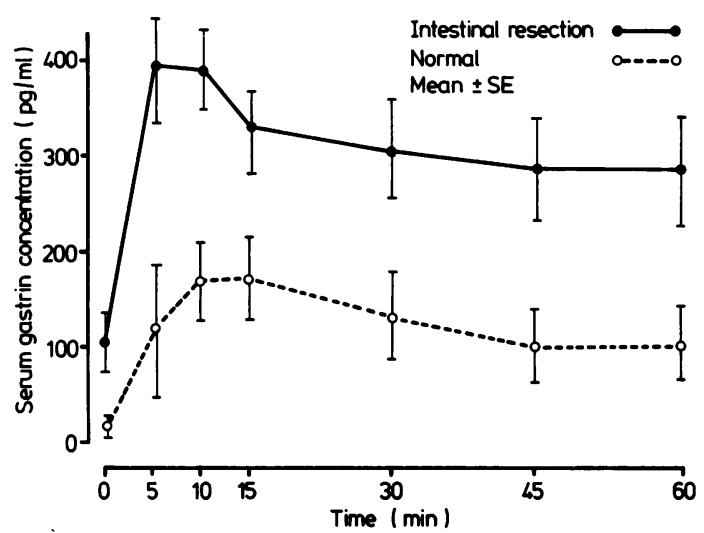

Fig. 3 Serum gastrin concentrations during period of intragastric titration. Integrated and peak responses were significantly greater $(p<0.05)$ in patients after resection compared with control subjects.

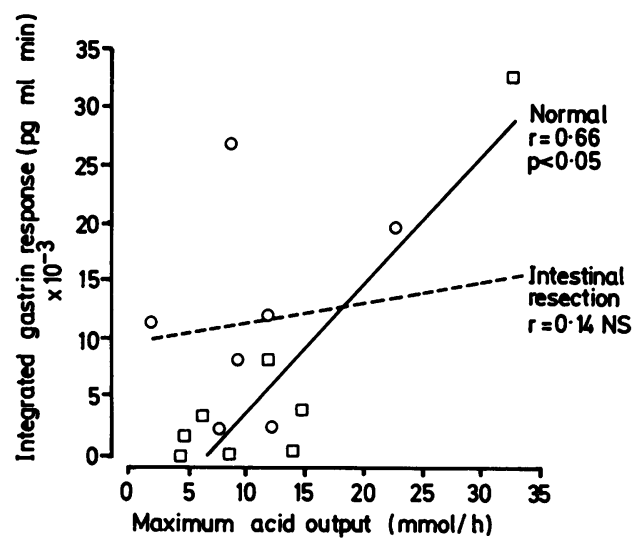

Fig. 4 Significant correlation between maximum acid output and serum gastrin response in normal subjects $\square$ but not in patients after resection $\bigcirc$. Correlation, however, in the normal subjects depends on one 'outlier'.

The same was true for the peak gastrin responses $450 \pm 109 \mathrm{pg} / \mathrm{ml}$ in patients compared with $174 \pm 98$ in controls $(\mathrm{p}<0.05)$.

Correlation of acid output and gastric concentration There was a significant positive correlation between maximum acid output and integrated gastrin response in normal subjects $(p<0.05)$, but this was clearly dependent on one outlier (Fig. 4). There was no correlation in the patients.

\section{Residual volumes}

There was no significant difference in volumes of gastric contents remaining in the stomach after 60 minutes in control subjects or patients. Volumes were $151 \pm 36.2$ and $125 \pm 23 \mathrm{ml}$ respectively.

\section{ASPIRATION STUDY}

Mean BAO in control subjects was $3.8 \pm 1.6 \mathrm{mmol} / \mathrm{h}$ and in patients was $3.7 \pm 1.7$ (NS). Mean PAO response to pentagastrin was $25.9 \pm 3.5 \mathrm{mmol} / \mathrm{h}$ in control subjects and in patients was 19.9 $\pm 5 \cdot 5$ $\mathrm{mmol} / \mathrm{h}$ (NS).

The results described above include the one patient with Crohn's disease. Exclusion of this patient does not affect the statistical conclusions.

\section{Discussion}

It is generally believed that after extensive resection of the small intestine in man there is an increase in the amount of gastric acid secreted. The abnormality has been explained by the finding that serum gastrin is raised in these patients. The results of our study although confirming the rise in serum gastrin 
previously observed have been unable to show that this is associated with a concomitant increase in acid secretion.

The evidence for increased acid production has primarily been derived from animal experiments. ${ }^{1} 320-22$ Although several case reports document acid hypersecretion after extensive small bowel resection in man few studies have measured acid production in a controlled manner. Thus, Aber et $a l^{2}$ carefully documented gastric secretion, urinary net hydrogen ion excretion and extracellular acid base state in one patient and concluded that acid hypersecretion resulted from resection. Similar conclusions were drawn by Krone $e t a l^{23}$ who found that the $\mathrm{pH}$ of jejunal contents in six patients after intestinal resection was low. Fielding $e^{2} a^{4}$ in a more detailed study showed that BAO and PAO in response to pentagastrin were significantly increased in eight male patients who had had $60 \mathrm{~cm}$ or more of their distal ileum resected for Crohn's disease compared with four patients who had an intact gastrointestinal tract. It is not stated if the two groups were similar with respect to age, sex, or body weight, factors which are of great importance in the interpretation of data from acid secretion studies. ${ }^{24}$

Our results are at variance from those reported by Fielding $\mathrm{et} \mathrm{al}^{4}$ in so far as no significant difference in BAO and PAO could be shown between our two groups of subjects. Differences in study design might explain this discrepancy. First, our patients and control subjects were very carefully matched not only for age and sex but also for body weight. In addition seven of our eight patients did not have Crohn's disease and if the one exception is excluded the conclusions remain unchanged. In studies which include patients with Crohn's disease it is not possible to be sure if observed differences between groups are because of resection of small bowel or because of the presence of residual disease. It should be noted, however, that although acid studies do not seem to have been undertaken in patients with Crohn's disease, several studies have shown normal fasting and postprandial concentrations of gastrin. ${ }^{25} 26$

Although several canine studies ${ }^{327-29}$ have examined acid output in response to a meal stimulus after small bowel resection, similar studies have not previously been done in man. Using the technique of intragastric titration we were able to do this, but as with measurements of PAO and BAO, we were unable to confirm those animal studies which showed hypersecretion. Although the method used did not utilise a solid meal, the meal stimulus did contain a balanced proportion of nutrients which are known to stimulate acid production by similar mechanisms. ${ }^{30}$ The technique of intragastric titra- tion can naturally be criticised as it manipulates intragastric $\mathrm{pH}$ and maintains it at a constant level. Nevertheless, it is more 'physiological' than aspiration techniques because not only can it measure acid secretion in response to food but it is not affected by changes in gastric emptying. ${ }^{31}$ The latter is of particular relevance in patients after ileal resection as recent studies suggest that the distal small bowel may control emptying by an inhibitory feedback mechanism. ${ }^{32}{ }^{33}$ It is of interest that in a recent canine study which used a similar method of intragastric titration to measure acid secretion in response to liver extract, massive small bowel resection caused gastric acid hyposecretion. In addition the same study showed that pentagastrin stimulated acid secretion remained unchanged after resection.

Since some reports 2227283435 have shown that proximal resection was more likely to increase acid output than distal resection it might be considered that any discrepancy between our results and those of others was related to this factor. Most of our patients, however, had considerable lengths of small bowel removed and although the distal ileum had always been resected a significant proportion of jejunum had also been excised. With regard to the length and site of resection, therefore, our patients were similar to experimental animals that showed hypersecretion. ${ }^{3621}$ Furthermore, in Fielding's study in man, ${ }^{4}$ hypersecretion occurred after $60 \mathrm{~cm}$ or more of distal small bowel had been resected. Allied to this point are the findings of Windsor $e a^{3}$ who could not correlate the extent of resection with the hypersecretion which occurred in their patients.

The finding of increased concentrations of serum gastrin are in agreement with other studies. ${ }^{911}$ The cause is obscure. The fact that the concentration of gastrin is greater in arterial blood than in mesenteric veins draining the distal small bowe ${ }^{37}$ suggests that the small bowel may be necessary for the metabolism of gastrin and that raised gastrin concentrations may be secondary to impaired degradation in this part of the gut. This hypothesis, however, seems unlikely. If there was a decreased degradation rate of gastrin in the patients there would be a prolonged delay involving the peak gastrin concentration and in its return towards basal levels. Yet the peak gastrin concentrations were achieved at the same time as in the control group and the subsequent fall off appeared similar in the two groups. Similar findings were noted by Strauss et al ${ }^{9}$ who, in fact, postulated that the cause for the hypergastrinaemia in their four patients might be because of the absence of an inhibitor in the small intestine. The likely candidates were considered at that time to be secretin, gastrointestinal inhibitory polypeptide and 
cholecystokinin (CCK). As the former two hormones have been shown to be localised primarily in the duodenum and proximal jejunum ${ }^{37} 38$ it seems unlikely that they are implicated. On the other hand CCK has recently been shown to be present throughout the small bowel ${ }^{39} 40$ and this hormone may be culpable. Similarly, somatostatin, another inhibitor of gastrin ${ }^{41}$ which is found throughout the ileum may also be involved. ${ }^{32}$

Whatever the cause of the raised concentrations of gastrin it is clear that in our patients they were not associated with acid hypersecretion. On the face of it this conclusion is further emphasised by the finding that whereas in normal subjects a positive correlation between serum gastrin and acid output existed this was not the case in the patients. Because, however, the correlation between these measurements in normal subjects was dependent on the one 'outlier' we are reluctant to draw firm conclusions from these data. The finding that acid secretion in resonse to exogenous pentagastrin was no different in patients and controls suggests that the fault is not an insensitivity of the parietal cell mass to endogenous gastrin. It may be that either an inhibitory substance to endogenous gastrin is present after resection or that the gastrin that is released is ineffective. The assay we used measured both $G_{17}$ and $G_{34}$. Because $G_{17}$ is mol for mol six times more potent in stimulating acid secretion than $\mathrm{G}_{34},{ }^{42}$ a rise in the latter of the magnitude found in our patients without a concomitant rise in $G_{17}$ would be unlikely to significantly affect acid secretion. This explanation would of course be dependent on the half lives of the two gastrins being identical in the resected group and the control group. This situation has been found to be the case in patients with chronic renal failure ${ }^{43}$

It is difficult to understand the purpose of the raised serum gastrin in these patients. It was considered at one time that because gastrin was trophic to gastrointestinal mucosa ${ }^{44}{ }^{45}$ it might play a role in the conpensatory changes which occur in the residual small bowel. ${ }^{46} 47$ Current evidence, however, suggests that gastrin does not fulfil either a physiological or pathophysiological role in the medication of these changes. ${ }^{48} 49$

From a clinical standpoint our findings are clear. Although no comment can be made about changes in the short term after extensive small bowel resection, in the long term acid hypersecretion does not occur. This finding also receives support from the fact that there is no clinical evidence which suggests an increased incidence of peptic ulceration in these patients. It therefore seems unnecessary to keep patients who have undergone this type of surgery on maintenance anti-ulcer therapy.
We thank Professor David Johnston for his advice and permission to study his patients. We are most grateful to Gwyneth Salter, Sheila Young and John Holmfield for skilled technical assistance, and we thank Lynne Lyndon and Lorna McQuade for secretarial assistance.

\section{References}

1 Landor JH, Baker WK. Gastric hypersecretion produced by massive small bowel resection in dogs. J Surg Res 1964; 4: 518-22.

2 Aber GM, Ashton F, Carmalt MHD, Whitehead TP. Gastric hypersecretion following massive small bowel resection in man. Am J Dig Dis 1967; 12: 785-94.

3 Windsor CWO, Fejfar J, Woodward DAK. Gastric secretion after massive small bowel resection. Gut 1969; 10: 779-86.

4 Fielding JF, Cooke WT, Williams JA. Gastric acid secretion in Crohn's disease in relation to disease activity and bowel resection. Lancet 1971; 1: 1106-7.

5 Fleming LR, Remington M. Chap. Intestinal failure. In: Hill GL ed. Nutrition and the surgical patient. Edinburgh: Churchill Livingstone, 1981.

6 Frederick PL, Craig TV. Effect of vagotomy and pyloroplasty on weight loss and survival of dogs after massive intestinal resection. Surgery 1964; 56: 135-40.

7 Osborne MP, Frederick PL, Sized JS, Blair P, Cole P, Thum W. Mechanism of gastric hypersecretion following massive intestinal resection. Clinical and experimental observations. Ann Surg 1966; 164: 622-31.

8 Cortot A, Fleming LR, Malagelada JR. Improved nutrient absorption after cimetidine in short bowel syndromes with gastric hypersecretion. $N$ Engl J Med 1979; 300: 79-80.

9 Strauss E, Gerson CD, Yalow RS. Hypersecretion of gastrin associated with the short bowel syndrome. Gastroenterology 1974; 66: 175-80.

10 Barros de Sa AAB, Buchanan KD. Role of gastrointestinal hormones in the response to massive resection of the small bowel. Gut 1979; 20: 806-10.

11 Besterman HJ, Adrian TE, Mallinson CN et al. Gut hormone release after intestinal resection. Gut 1982; 23: 854-61.

12 Taylor TV, Elder JB, Ganguli PC, Gillespie IE. Comparison of an intragastric method of estimating acid output with the pentagastrin test in normal and duodenal ulcer patients. Gut 1978; 19: 865-69.

13 Fordtran JS, Walsh JH. Gastric acid secretion rate and buffer content of the stomach after eating. Results in normal subjects and in patients with duodenal ulcer. $J$ Clin Invest 1973; 52: 645-57.

14 Lam SK, Isenberg JI, Grossman MI, Lane WJ, Walsh JH. Gastric acid secretion in abnormally sensitive to endogenous gastrin released after peptone test meals in duodenal ulcer patients. J Clin Invest 1980; 65: 555-63.

15 Stadil F, Rehfeld JF, Christiansen LA, Malmstrom J. Patterns of gastrin components in serum during feeding in normal subjects and duodenal ulcer patients. Scand J Gastroenterol 1975; 77: 863-8. 
16 Rehfeld JF, Stadil F, Vikelsoe J. Immunoreactive gastrin components in human serum. Gut 1974; 15: 102-11.

17 Rehfeld JF. A unique high titre antiserum to gastrin. Scand J Clin Lab Invest 1981; 41: 723-7.

18 Baron JH. Timing of peak acid output after pentagastrin. Gastroenterology 1969; 56: 641-3.

19 Snedecor GW, Cochran WC. Statistical methods. Iowa, USA: State University Press.

20 Frederick PL, Sizer JS, Osborne MP. Relation of massive bowel resection to gastric secretion. $N$ Engl J Med 1965; 272: 509-14.

21 Reul GJ, Ellison EH. Effect of seventy-five per cent distal small bowel resection on gastric secretion. $A m \mathrm{~J}$ Surg 1966; 111: 772-6.

22 Santillana M, Wise L, Schuck M, Ballinger WF. Changes in gastric acid secretion following resection or exclusion of different segments of the small intestine. Surgery 1969; 65: 777-82.

23 Krone CL, Theodor E, Sleisenger MH, Jeffries GH. Studies on the pathogenesis of malabsorption, lipid hydrolysis and micelle formation in the intestinal lumen. Medicine (Balt.) 1968; 47: 89-106.

24 Baron JH. Clinical tests of gastric secretion. London \& Basingstoke, MacMillan. 1978.

25 Besterman HS, Mallinson CN, Modigliani R et al. Gut hormones in inflammatory bowel disease. Scand $J$ Gastroenterol 1983; 18: 845-52.

26 Spence RAJ, Willoughby Wilson, Alam MJ, Ardil JES, Buchanan KD, Merrett JD. Gastrointestinal hormones in inflammatory bowel disease. $J R$ Coll Surg Edin 1983; 28: 313-6.

27 Copeland EM, Miller LD, Smith GP. The complex nature of small bowel control of gastric secretion. Ann Surg 1968; 168: 36-45.

28 Landor JH, Behringer BR, Wild RA. Postenterectomy gastric hypersecretion in dogs; the relative importance of proximal versus distal resection. J Surg Res 1970, 11: 238-42.

29 Seal AM, Debas HT, Reynolds C, Said SI, Taylor IL. Gastric and pancreatic hyposecretion following massive small bowel resection. Dig Dis Sci 1982; 27: 117-23.

30 Giles GR, Clark CG. Gastric secretion stimulated by meal extract in man. A test of antral function. Scand $J$ Gastroenterol 1966; 1: 159-66.

31 Feldman M, Richardson CT. Chap. Gastric acid secretion in human. In: Johnson LR, ed Physiology of the gastrointestinal tract. New York: Raven Press, 1981.

32 MacFarlane A, Kinsman R, Read NW, Bloom JR. The ileal brake: ileal fat slows small bowel transit and gastric emptying in man. [Abstract] Gut 1983; 24: A471-2.

33 Spiller RC, Trotman IF, Higgins BE et al. Inhibition of jejunal motility by ileal fat infusion in man. [Abstract]
Gut 1983; 24: A472.

34 Sabsai B. The effect of extensive resection of the proximal and distal portions of the small intestine on canine gastric secretion. Bull Exp Biol Med 1963; 55: 387-90.

35 Westerheide RL, Elliot DW, Hardacre JM. The potential of the upper small bowel in regulating acid secretion. Surgery 1965; 58: 73-81.

36 Polak JM, Colling I, Bloom SR, Pearse AGE. Immunofluorescent localisation of secretion and enteroglucogon in human intestinal mucosa. Scand $J$ Gastroenterol 1971; 6: 739-44.

37 Walsh JH, Grossman MI. Gastrin. N Engl J Med 1975; 292: 1324-34.

38 Buffa R, Polak JM, Pearse AG, Solcia E, Grimelius L, Capella C. Identification of the intestinal cell storing gastric inhibitory polypeptide in man. Histochemistry 1975; 43: 249-55.

39 Buchan AMJ, Polak JM, Solcia E, Capella C, Hudson D, Pearse AGE. Electron immunohistochemical evidence for the human intestinal I cell as the source of CCK. Gut 1978; 19: 403-7.

40 Larsson LI, Rehfeld JF. Distribution of gastrin and CCK cells in the rat gastrointestinal tract. Histochemistry 1978; 58: 23-31.

41 Raptis S, Dollinger HC, Von Berger L, Schlegel W, Schroder KE, Pfeiffer EF. Effects of somatostatin and gastric secretion and gastrin release in man. Digestion 1975; 13: 15-26.

42 Walsh JH, Maxwell V, Isenberg JI. Biological activity and clearance of human big gastrin in man. Clin Res 1975; 23: 259.

43 Taylor IL, Dockray GJ. Hypergastrinaemia in renal failure: the biological significance of molecular forms of gastrin. Br J Surg 1977; 64: 657.

44 Barrowman JA. The trophic action of gastrointestinal hormones. Digestion 1975; 12: 92-104.

45 Johnson LR. The trophic action of gastrointestinal hormones. Gastroenterology 1976; 70: 278-88.

46 Dowling RH, Booth CC. Structural and functional changes following small intestinal resection in the rat. Clin Sci 1967; 32: 139-49.

47 Williamson RCN. Intestinal adaptation. Part 1. Structural, functional and cytokinetic changes. Part 2. Mechanisms of control. $N$ Engl J Med 1978; 298: 1393-402: 1444-50.

48 Oscarson JEA, Veen HF, Williamson RCN, Ross SJS, Molt RA. Compensatory postresectional hyperplasia and starvation atrophy in small bowel: dissociation from endogenous gastrin levels. Gastroenterology 1977; 72: 890-95.

49 Weser E. Role of gastrin in intestinal adaptation after small bowel resection. Gastroenterology 1978; 75: 323-4. 